\title{
Cooling Rate Sensitivity of RE-Containing Grain Refiner and Its Impact on the Microstructure and Mechanical Properties of A356 Alloy
}

\author{
Hua-Rui Zhang ${ }^{1,2} \cdot$ Zhen-Bang Liu ${ }^{1,2} \cdot$ Zi-Zhuo $\mathrm{Li}^{1,2} \cdot{\text { Guo-Wei } \mathrm{Li}^{3} \cdot \text { Hu Zhang }}^{1,2}$
}

Received: 30 December 2015/Revised: 28 January 2016/Published online: 22 March 2016

(C) The Chinese Society for Metals and Springer-Verlag Berlin Heidelberg 2016

\begin{abstract}
The cooling rate sensitivities of AlTiB, RE and AlTiB-RE refiners were investigated using laboratory experiments and the actual industrial applications of A356 automotive wheel via low pressure die casting technology. Their impact mechanisms on the microstructure and mechanical properties of the A356 alloy were discussed. The results demonstrated that the AlTiB-RE refiner possessed most effective and synergetic refinement effects compared to the individual AlTiB or RE refiners. The AlTiB-RE refiner exhibited the least sensitivity to the cooling rate changes than the other refiners. The comprehensive properties of alloy wheel refined by the AlTiB-RE refiner were improved significantly. The tensile strength, yield strength, and elongation of wheel spoke improved by approximately $11.3 \%, 10.8 \%$ and $44.1 \%$, respectively. The property difference values of the tensile strength, yield strength, and elongation in different positions of the wheel decreased from $14.8 \%, 31.2 \%$ and $47.7 \%$ to $8.6 \%, 27.1 \%$ and $30.9 \%$, respectively.
\end{abstract}

\section{KEY WORDS: Grain refinement; Cooling rate sensitivity; A356 alloy; Microstructure; Mechanical properties}

\section{Introduction}

The Al-Si casting alloys, such as A356 alloys, have been widely used in the automotive, military, and aerospace industries because of their excellent castability, good corrosion resistance, and high strength to weight ratios [1,2]. To improve the mechanical properties of these alloys, grain refinement and modification techniques by refining the

Available online at http://link.springer.com/journal/40195

\section{Hu Zhang}

zhanghu@buaa.edu.cn

1 School of Materials Science and Engineering, Beihang University, Beijing 100191, China

2 Beijing Key Laboratory for Advanced Functional Material and Thin Film Technology, Beihang University, Beijing 100191, China

3 SMX Dicastal Wheel Manufacture Company, Sanmenxia 472000, China micro-constituents, namely $\alpha$-Al and eutectic silicon particles, were utilized [3, 4]. The introduction of inoculating particles in the form of master alloys, such as Al-Ti-B, Al$\mathrm{Ti}-\mathrm{C}$, and $\mathrm{Al}-\mathrm{B}$, into $\mathrm{Al}-\mathrm{Si}$ alloy melts was one of the most effective ways to refine grains $[5,6]$.

Among the grain refiners, Al-Ti-B master alloys, particularly Al5TiB, have been most widely used in the Al-Si alloys over decades, as reported by Schneider [7]. A15TiB contains $\mathrm{Al}_{3} \mathrm{Ti}$ intermetallic compound and $\mathrm{TiB}_{2}$ particles in an aluminum matrix. Based on the studies of Greer et al. [8] and Han et al. [5], the $\mathrm{TiB}_{2}$ particles could act as heterogeneous nuclei to promote the crystallization of $\alpha$-Al grains. Recently, $\mathrm{Xu}$ et al. [9] found that the addition of rare earth (RE) elements in the preparation process of $\mathrm{Al}-$ Ti-B grain refiner could decrease the size of $\mathrm{Al}_{3} \mathrm{Ti}$, which improved the refining efficiency of $\mathrm{Al}-\mathrm{Ti}-\mathrm{B}$ refiner. Wang et al. [10] prepared novel AlTiB-RE nanorefiners by meltspinning in a LZK-12A-type vacuum quenching furnace using the raw materials of commercial $\mathrm{Al}-5 \mathrm{Ti}-\mathrm{B}$ rods and Ce-rich mischmetal. The application of novel AlTiB-RE 
nanorefiners showed that the RE hindered the nucleating particles from aggregating and precipitating. This effect prolonged the fading time of refining and improved the refining efficiency [11].

Moreover, the RE elements have special physicochemical activity and might be capable of contributing to the modification of eutectic $\mathrm{Si}$ in $\mathrm{Al}-\mathrm{Si}$ alloys, as reported by Sebaie et al. [12] and Li et al. [13]. Jiang et al. [14] showed that the addition of mischmetal containing $\mathrm{La}$ and $\mathrm{Ce}$ improved the morphology of eutectic Si particles compared to the unmodified A357 alloy and reduced the size of the $\alpha$ Al primary phase. For A356 alloys, Tsai et al. [15] reported that the efficiency of modification of microstructures and the mechanical properties with the addition of $1.0 \mathrm{wt} \% \mathrm{La}$ was similar to that of a commercial $\mathrm{Sr}$ modifier (0.01 wt $\%)$.

Although efforts have been made toward improving the refining efficiency of conventional AlTiB refiners by addition RE elements, in the case of novel AlTiB-RE or $\mathrm{RE}$ refiners, most of the previous research has been conducted at the laboratory scale. There is a lack of detailed investigation performed at an industrial scale. In the case of the conventional AlTiB grain refiners, one of the major problems during their actual industrial application is that the refining effects are sensitive to the cooling rates. For instance, when the Al5TiB grain refiner is applied in A356 automotive wheel by the low pressure die casting (LPDC) technology, the refining effect is met in the thin-walled regions of the wheel, such as the rims with a high cooling rate. However, the grain size in the thick walled regions, such as the wheel spokes, could be as high as $2-3 \mathrm{~mm}$, and these regions possess a low cooling rate. The sensitivity of the grain refining effects to the cooling rate leads to a significant variance in the mechanical properties of the different regions of the wheel.

However, the sensitivity of the RE-containing grain refiners to the cooling rate and its mechanism have not been investigated well. In particular, the refiner's cooling rate sensitivity during an actual industrial process of casting complex-shaped products with varying wall thickness has not been reported to date. Such information is of great importance in improving the comprehensive mechanical properties of complex-shaped alloy products during an actual industrial application.

Therefore, in this work, the cooling rate sensitivity of AlTiB-RE, RE, and conventional AlTiB refiners has been investigated via designed experiments in the laboratory and actual industrial applications of the A356 alloy automotive wheel produced by the LPDC technology. The results from these three cases were compared, and the impact mechanisms on the microstructure and mechanical properties of the A356 alloy were accordingly discussed.

\section{Experimental Procedure}

\subsection{Refining Effect}

The raw material used in this study was a commercial A356 alloy with a chemical composition given in Table 1 . Melting was performed in an electrical resistance furnace at $(740 \pm 5){ }^{\circ} \mathrm{C}$. Three different types of the grain refiners, i.e., Al5TiB, RE, and AlTiB-RE were added to the Srmodified A356 alloy melt. The holding time was $30 \mathrm{~min}$. The RE was mischmetal and contained $60 \% \mathrm{Ce}$ and $40 \%$ La elements. The addition of the AlTiB-RE refiner was in the form of combined use of Al5TiB and AlloRE mater alloy to minimize the formation of AlSiTiRE intermetallic compounds with large size. The concentrations added were $0-0.4 \mathrm{wt} \%$ for RE and $0-1 \mathrm{wt} \%$ for Al5TiB.

To evaluate the cooling rate sensitivity of the grain refiners, the alloy melt was poured into a taper-shaped graphite mold, as shown in Fig. 1a. Using this configuration of a mold, the cooling rate decreases with the increase in the thickness of the samples. K-type thermocouples were inserted at different locations of the mold and connected to a data acquisition system to record the solidification parameters during the cooling process. The cooling curves are shown in Fig. 1b, and the average cooling rates ranged from 1.5 to $32{ }^{\circ} \mathrm{C} / \mathrm{s}$.

\subsection{Industrial Applications}

The industrial applications of the refiners were carried out in the SMX Dicastal Wheel Manufacture Company. The A356 automotive wheels with $35.56 \mathrm{~cm}$ (14 in.) in diameter and $11.43 \mathrm{~cm}$ (4.5 in.) in width were casted by the LPDC technique. The alloy wheel with a conventional concentration of $0.3 \mathrm{wt} \%$ Al5TiB refiner was firstly produced as a reference. AlTiB-RE with concentration of $0.3 \mathrm{wt} \%$ was added to the $1200-\mathrm{kg}$ weighted tundish. The holding time of the refiners in tundish was about $30 \mathrm{~min}$. After degassing and deslagging, the molten A356 alloy in the tundish was transferred to the electrically heated holding furnace. The injection temperature of LPDC was approximately $(695 \pm 5){ }^{\circ} \mathrm{C}$. The process began with the pressurization of the furnace. The increased pressure in the furnace forced liquid aluminum up transfer tubes into the die cavities, where it was cooled and solidified by the transfer of heat from the aluminum to the die and subsequently out to the environment. After the solidification was complete, the side dies opened, and the top die was raised vertically. The wheel was ejected onto a transfer tray. Next, the die was closed, and the cycle began again. Typical cycle time is 5-6 min. Then the wheel was subjected to a $\mathrm{T} 6$ heat treatment. The details of the T6 treatment are listed 
Table 1 Chemical composition of A356 alloys (wt\%)

\begin{tabular}{llllllllll}
\hline $\mathrm{Si}$ & $\mathrm{Mg}$ & $\mathrm{Ti}$ & $\mathrm{Sr}$ & $\mathrm{Fe}$ & $\mathrm{Cu}$ & $\mathrm{Mn}$ & $\mathrm{Zn}$ & $\mathrm{Ga}$ & $\mathrm{Al}$ \\
\hline 7.190 & 0.263 & 0.112 & 0.0146 & 0.111 & $<0.001$ & 0.007 & $<0.001$ & 0.0111 & $\mathrm{Bal}$. \\
\hline
\end{tabular}
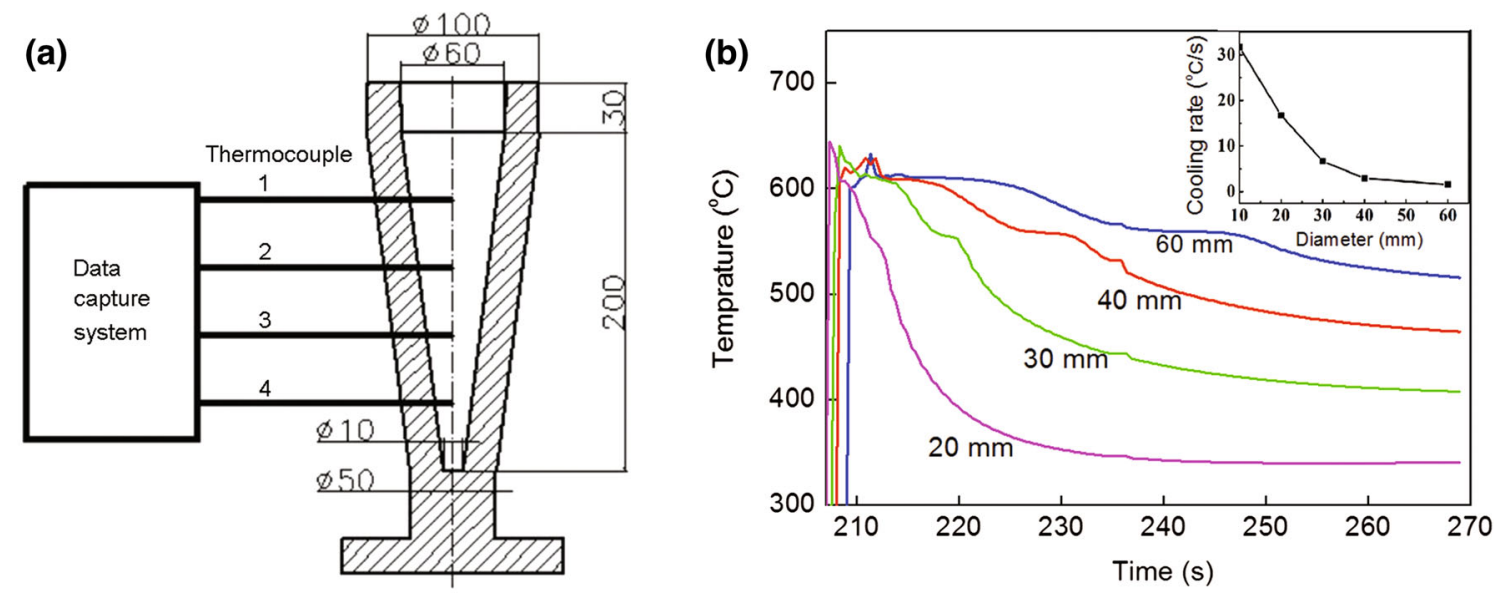

Fig. 1 a Schematic of taper-shaped graphite mold and thermocouple positions; b Cooling curves of different sections with various diameters in the mold. The inset further reveals the measured average cooling rates

Table 2 Detailed conditions for the solution treatment and artificial aging during $\mathrm{T} 6$ treatment

\begin{tabular}{lllll}
\hline Solution treatment & & & \multicolumn{2}{l}{ Artificial aging } \\
\cline { 1 - 1 } \cline { 5 - 5 } Temperature $\left({ }^{\circ} \mathrm{C}\right)$ & Time $(\min )$ & & Temperature $\left({ }^{\circ} \mathrm{C}\right)$ & Time $(\min )$ \\
\hline 540 & 240 & 155 & 180 \\
\hline
\end{tabular}

in Table 2. The concentrations of RE in final wheels were measured by an inductively coupled plasma-atomic emission spectroscopy (ICP-AES) apparatus. The samples taken from the hub, spoke, and the rim sections of the wheels were processed for microstructural and mechanical analysis (Fig. 2). The tensile samples were of a plate-type, and the gauge length and width were 30 and $6 \mathrm{~mm}$, respectively. The approximate cooling rates of hub, spoke, and the rim sections calculated according to the size of secondary dendrite arm spacing were $0.26,0.54$, and $4.2{ }^{\circ} \mathrm{C} / \mathrm{s}$, respectively.

\subsection{Microstructural Analysis}

The samples were mechanically polished following standard metallographic procedures. The samples for the grain size analysis were etched using a mixture of $\mathrm{HCl}$ and $\mathrm{HNO}_{3}$ ( $\mathrm{HCl}: \mathrm{HNO}_{3}=3: 1$ ) for 20-60 s. Average grain size values were obtained using a linear intercept method. Microscopic observation was performed by using an OLYMPUSBX51 M optical microscope. The microstructure of the samples was characterized by an electron probe micro-

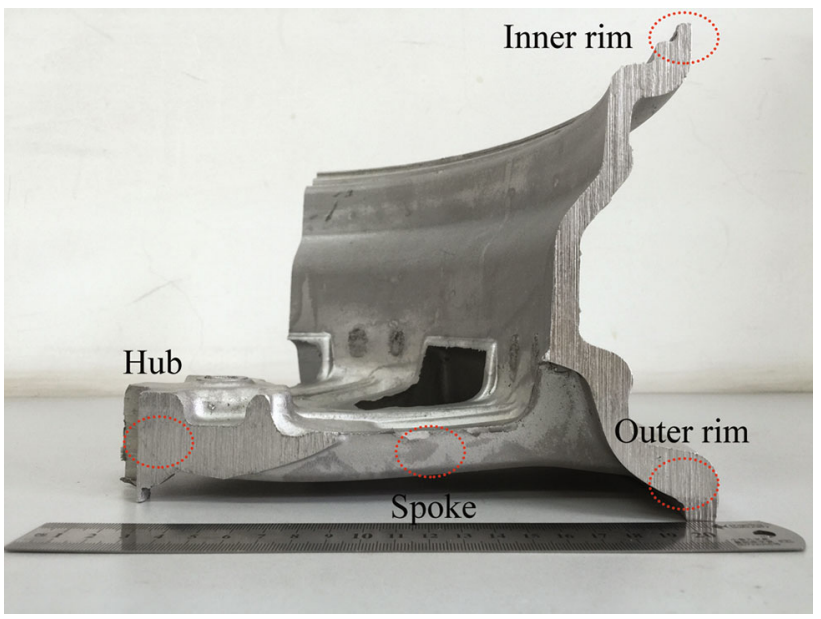

Fig. 2 Positions on the hub, spoke, and the rim regions from where the samples were taken

analyser (EPMA, JEOL JXA-8100). Elemental compositions were analyzed by an energy-dispersive spectrometer (EDS, Oxford INCAPentaFET-x3).

\subsection{Mechanical Tests}

An extensometer (INSTRON 8801) was used to perform tension tests at the room temperature under a strain rate of $2.7 \times 10^{-4}$. The cross-head speed was $1 \mathrm{~mm} / \mathrm{min}$. The strain was measured over a gauge length of $30 \mathrm{~mm}$. Proof stress of $0.2 \%$ was reported as the yield stress. The hardness of the A356 alloy was measured using an HB- 

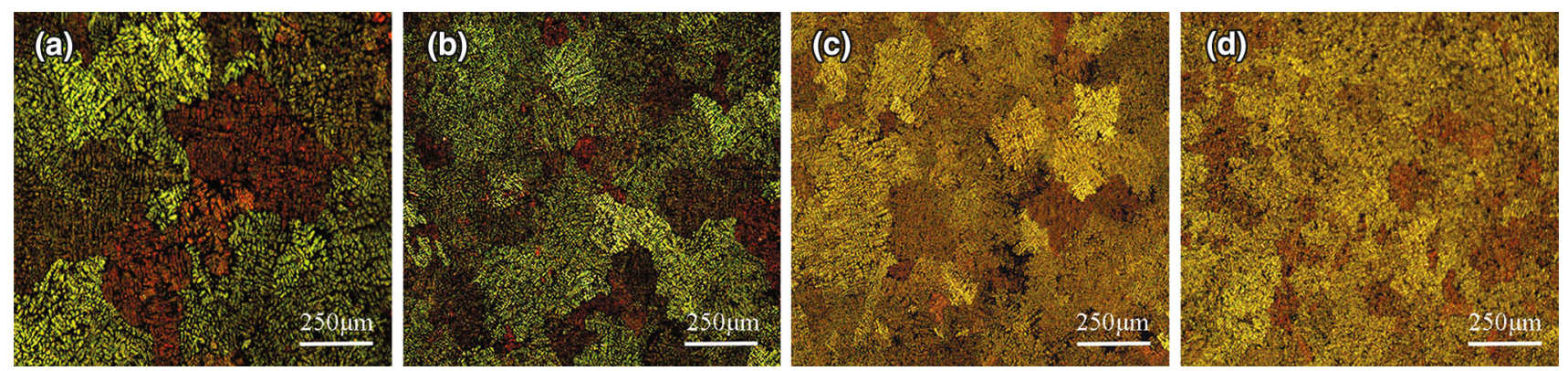

Fig. 3 Typical optical micrographs of the samples without and with grain refiners at $3{ }^{\circ} \mathrm{C} / \mathrm{s}$ : a without refiners; b $0.3 \mathrm{wt} \% \mathrm{AlTiB}$; c $0.3 \mathrm{wt} \% \mathrm{RE}$; d 0.3 wt $\%$ AlTiB-RE

3000 hardness testing machine with an indentation load of $250 \mathrm{~kg}$ for $15 \mathrm{~s}$. At least six samples were analyzed for each of the tensile and the hardness tests.

\section{Results}

\subsection{Refining Effect of Different Grain Refiners}

The typical optical micrographs of the A356 alloy samples without any refiner addition and that of the samples containing AlTiB, RE, and AlTiB-RE grain refiners are shown in Fig. 3. The grain size of the A356 alloy that was refined after refinering were added can be observed.

Figure 4 shows the variation of the average grain size with different content of the refiners under different cooling rates. The refining effect of AlTiB refiner increased with increasing AlTiB content at different cooling rates. When the alloy contained the RE refiner, it presented different refining characteristics at various cooling rates. In the case of relatively high cooling rates $\left(17-32{ }^{\circ} \mathrm{C} / \mathrm{s}\right)$, the refining effect increased with increasing RE content, as expected. In the case of $0.4 \mathrm{wt} \% \mathrm{RE}$ at a cooling rate of $32{ }^{\circ} \mathrm{C} / \mathrm{s}$, the average grain size of the alloy decreased by $38.8 \%$ (from 273 to $167 \mu \mathrm{m}$ ). In the case of relatively low cooling rates $\left(1.5-3{ }^{\circ} \mathrm{C} / \mathrm{s}\right)$, the refining effect greatly declined and the refinement extent fluctuated between $1.8 \%$ and $7.9 \%$.

For the AlTiB-RE refiner, refinement was much greater than the individual addition of the AlTiB refiner or the RE refiner at the same conditions. Also, the refinement level increased with increasing concentration of AlTiB-RE. The minimum grain size decreased to $119 \mu \mathrm{m}$ by $56.4 \%$ at $32{ }^{\circ} \mathrm{C} / \mathrm{s}$. This finding indicated that the AlTiB and RE had synergetic refinement effects and AlTiB-RE is a highly effective grain refiner.

\subsection{Cooling Rate Sensitivity of Grain Refiners}

To discuss the sensitivity of different refiners to the cooling rate, the refining effects of three refiners with the same concentrations $(0.3 \mathrm{wt} \%)$ were compared under the same cooling conditions. Typical grain size versus cooling rate curves for the alloy samples are shown in Fig. 5a. It can be clearly observed that the cooling rate greatly affected the grain size of alloy. The average grain size decreased with increasing cooling rate.

Figure $5 b$ shows the refining effect of different refiners as a function of the cooling rate. The refining level changes with a change in the cooling rate were almost linear for all the refiners. The cooling rate sensitivity of different refiners could be analyzed from the slopes of the lines. It can be clearly observed that the order of slopes was $\mathrm{RE}>\mathrm{AlTiB}>\mathrm{AlTiB}-$ $\mathrm{RE}$, illustrating that the AlTiB-RE refiner showed the lowest sensitivity to the cooling rate among the three refiners.

Figure 6 shows the average grain sizes of different sections in the A356 alloy wheel produced by the LPDC technique with an addition of the AITiB-RE refiner and the AlTiB refiner. When the cooling rate varied from the wheel hub to the inner rim sections, the average grain size decreased by $21.3 \%$ (from 549 to $432 \mu \mathrm{m}$ ) as the AlTiB refiner concentration increased in the alloy. The average grain size further decreased from 448 to $394 \mu \mathrm{m}$ when the AlTiB-RE refiner was added. The extent of variation of the refining effect with the AlTiB-RE addition was only $10.6 \%$ $12.1 \%$, while that with the addition of the AlTiB refiner was $43.2 \%-50.2 \%$ under the same cooling conditions. This showed that the AlTiB-RE refiner remarkably reduced the cooling rate sensitivity of the $\mathrm{AlTiB}$ grain refiner in an actual industrial practice.

\subsection{Microstructure}

Figure 7 shows the microstructure of different sections in the A356 alloy wheel with the addition of AlTiB-RE and conventional AlTiB refiners. Table 3 lists the chemical compositions of the typical phases in Fig. 7. The microstructure of the wheels consisted of $\alpha$ - $\mathrm{Al}$ dendrites, surrounded by well-modified eutectic Si particles, and $\mathrm{Fe}$ based intermetallic compounds. Typical needle-shaped $\beta$ $\left(\mathrm{Al}_{5} \mathrm{FeSi}\right)$ phase (A phase) with approximately $200 \mu \mathrm{m}$ in 

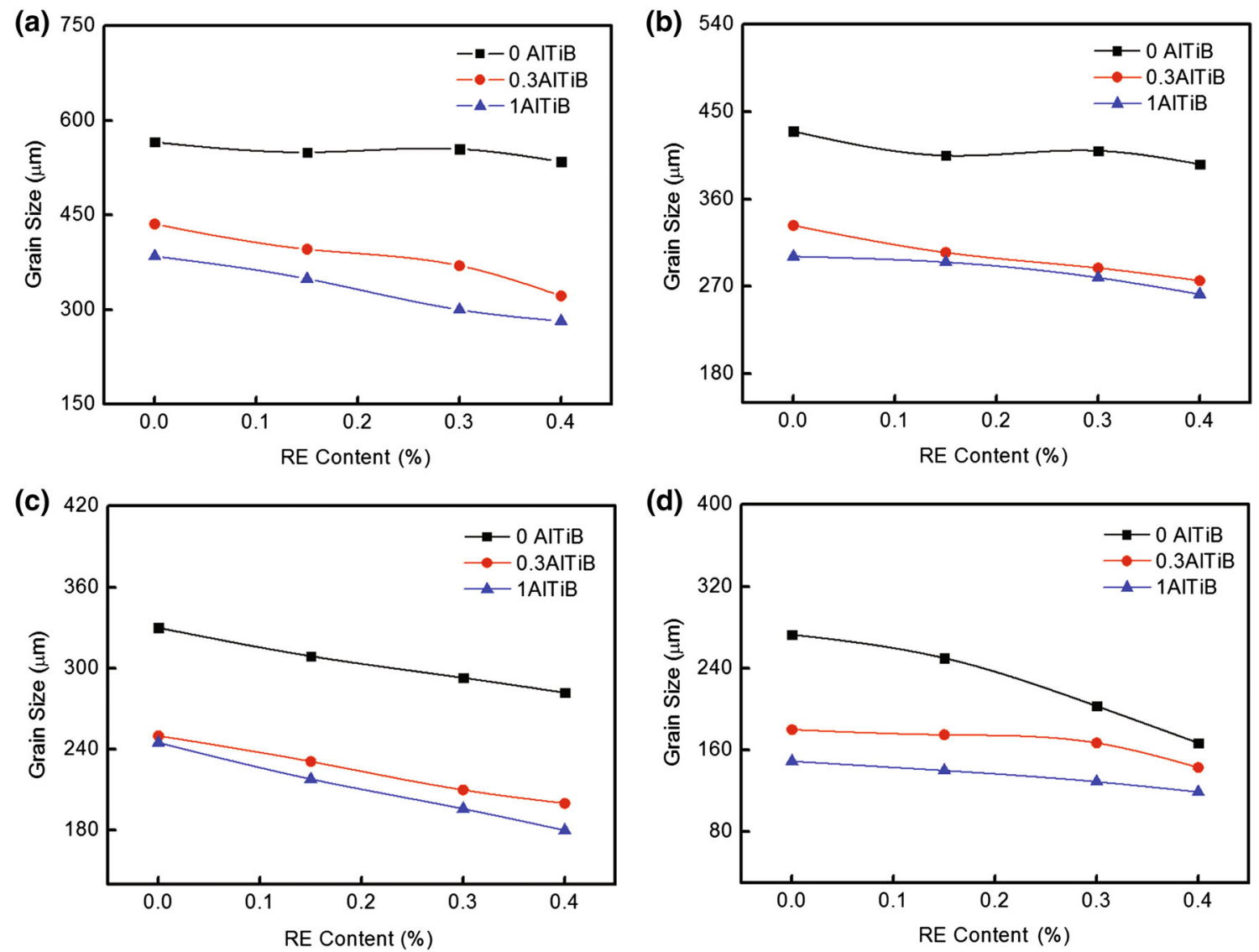

Fig. 4 Average grain size with varying refiner contents and varying cooling conditions: a $1.5{ }^{\circ} \mathrm{C} / \mathrm{s} ; \mathbf{b} 3{ }^{\circ} \mathrm{C} / \mathrm{s} ; \mathbf{c} 17^{\circ} \mathrm{C} / \mathrm{s} ; \mathbf{d ~} 32{ }^{\circ} \mathrm{C} / \mathrm{s}$
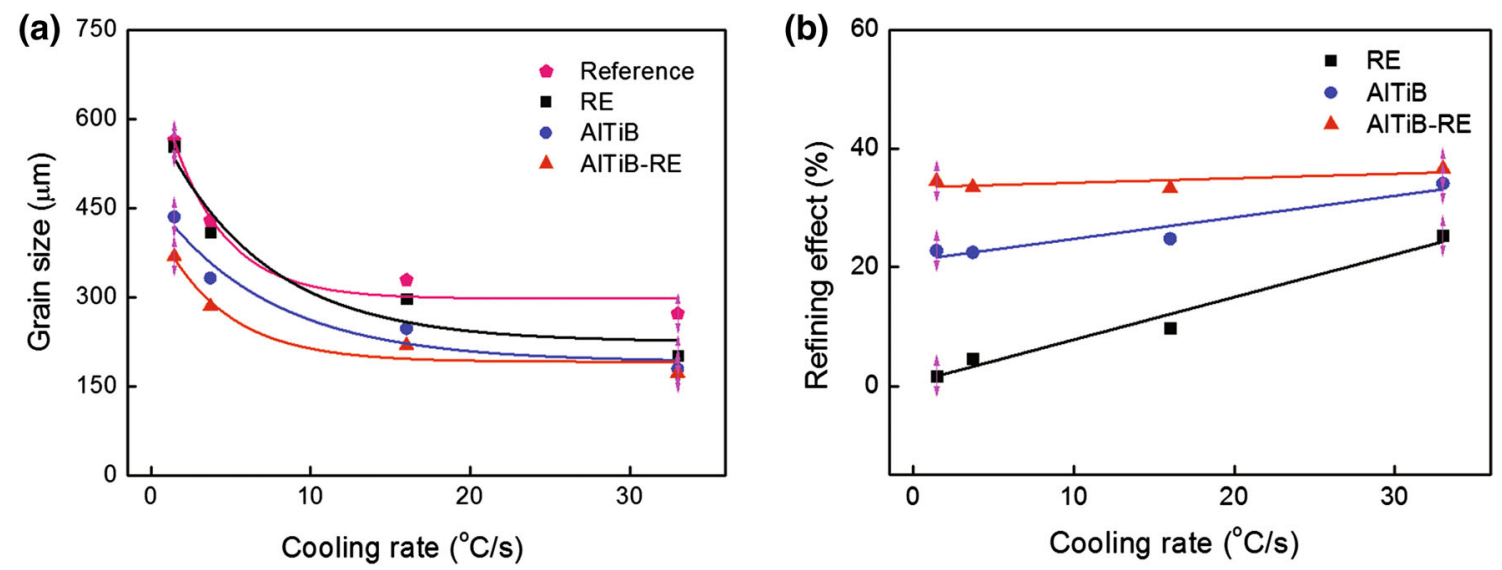

Fig. 5 a Typical average grain size as a function of the cooling rate for the samples without a refiner and the samples with the addition of different refiners. The addition concentration was $0.3 \mathrm{wt} \%$ for each refiner; $\mathbf{b}$ Refining effect of different refiners as a function of the cooling rate

length was detected in the alloy refined by AlTiB, which had an adverse effect on the alloy properties. After the AlTiB-RE refiner was added into the alloy, the $\alpha$-Al refined with better modification of the eutectic Si. The size of $\beta$ - $\left(\mathrm{Al}_{5} \mathrm{FeSi}\right)$ phase decreased noticeably (D phase). Moreover, block-like AlSiTiRE intermetallic compounds
(B and $\mathrm{C}$ phases) were formed. The compounds were predominantly present in the interdendritic regions, not only in the spokes but also in the rims.

However, when the content of RE further increased to $0.16 \mathrm{wt} \%$, ribbon-shaped REFeSiTiSr compounds (E phase) with a size of approximately $50 \mu \mathrm{m}$ were formed. 


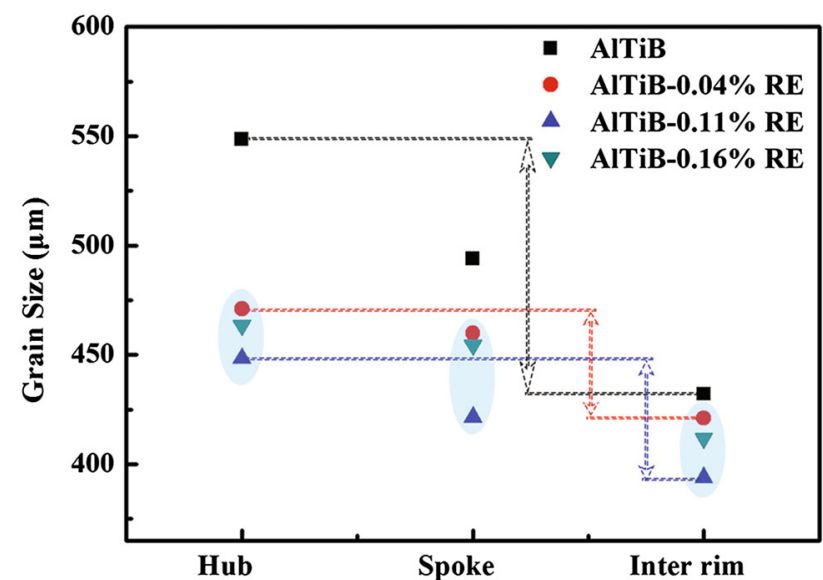

Fig. 6 Average grain sizes of different sections of the wheel made of A356 alloy with an addition of AlTiB-RE and conventional AlTiB refiners

\subsection{Mechanical Properties}

The mechanical properties of different sections of the A356 alloy wheel with the addition of AlTiB and AlTiB-RE refiners are shown in Fig. 8. Compared to the alloy refined by AITiB, the properties of the alloy wheel refined by AlTiB-RE refiner significantly were improved. With an
Table 3 Chemical compositions of typical phase in Fig. 7 (at.\%)

\begin{tabular}{lllllllll}
\hline Phase & $\mathrm{Al}$ & $\mathrm{Si}$ & $\mathrm{Mg}$ & $\mathrm{Sr}$ & $\mathrm{La}$ & $\mathrm{Ce}$ & $\mathrm{Fe}$ & $\mathrm{Ti}$ \\
\hline $\mathrm{A}$ & 68.07 & 17.21 & & & & & 14.72 & \\
$\mathrm{~B}$ & 74.25 & 14.51 & 0.83 & & 2.01 & 5.88 & 1.28 & \\
$\mathrm{C}$ & 60.72 & 18.00 & & 1.35 & 0.61 & 0.97 & 15.48 & 2.77 \\
$\mathrm{D}$ & 70.12 & 16.22 & & & & & 13.65 & \\
$\mathrm{E}$ & 37.09 & 40.06 & 0.97 & 0.60 & 3.46 & 7.75 & 11.07 & \\
\hline
\end{tabular}

increase in the RE content, from 0 to $0.11 \mathrm{wt} \%$, the properties gradually were improved. The tensile strength of the spoke and the inner rim were improved by $11.3 \%$ (from approximately $230-256 \mathrm{MPa}$ ) and by $3.7 \%$ (from approximately 270-280 MPa), respectively. The tensile strength difference between the spoke and the inner rim decreased from $14.8 \%$ to $8.6 \%$ because of the RE addition. The yield strength of the spoke and the inner rim increased from approximately 148 and $215 \mathrm{MPa}$ to 164 and $225 \mathrm{MPa}$, respectively. This increase was equivalent to an increase by almost $10.8 \%$ and $4.7 \%$, respectively. The difference between the spoke and the inner rim decreased from $31.2 \%$ to $27.1 \%$. The elongation also increased by approximately $44.1 \%$ (spoke) and $9.2 \%$ (inner rim), and the difference between the elongation of the two sections decreased from
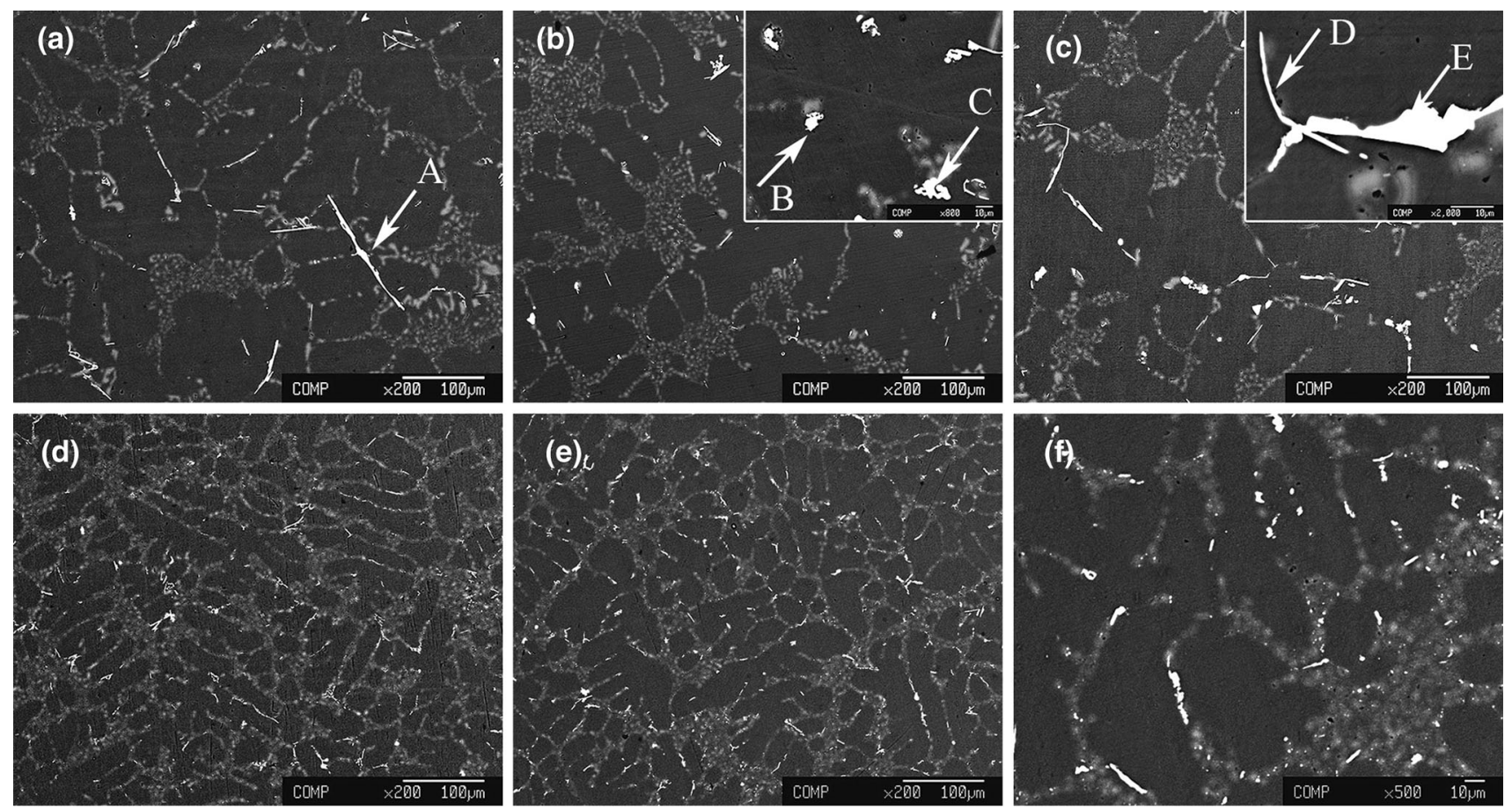

Fig. 7 Microstructure of different sections of the A356 alloy wheel with the addition of AlTiB and AlTiB-RE refiners: a spoke with the addition of the AlTiB refiner; $\mathbf{b}$ spoke with the addition of the AlTiB- $0.11 \%$ RE refiner; $\mathbf{c}$ spoke with the addition of the AlTiB-0.16\% RE refiner; $\mathbf{d}$ inner rim with the addition of the AlTiB refiner; $\mathbf{e}$ inner rim with the addition of the AlTiB- $0.11 \%$ RE refiner; $\mathbf{f}$ a typical higher magnification of $\mathbf{e}$ 

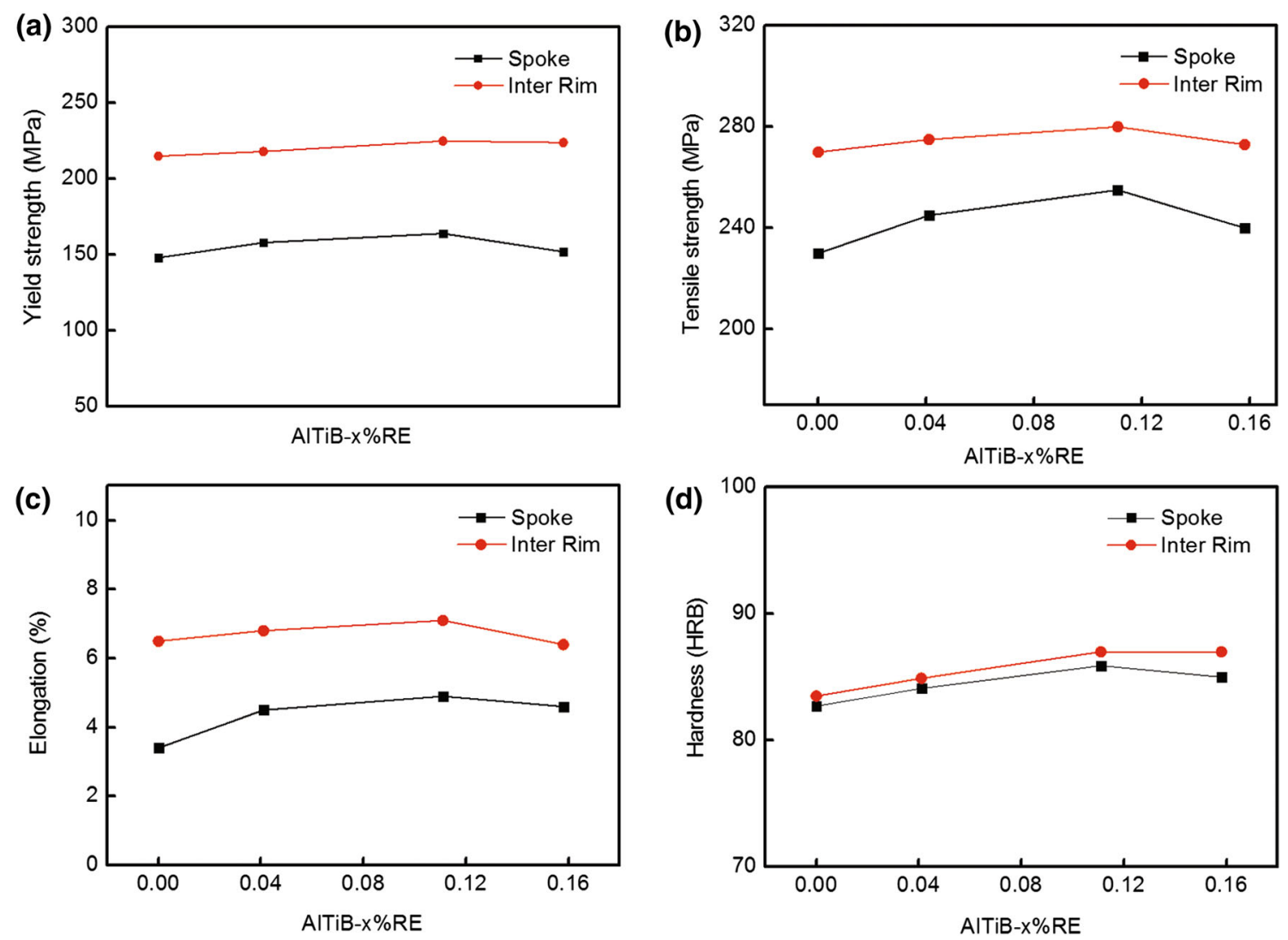

Fig. 8 Mechanical properties of the A356 alloy wheel with different refiners

$47.7 \%$ to $30.9 \%$. The hardness of the alloy wheel increased slightly.

These results suggest that the improvement levels for the wheel spokes with a low cooling rate were considerably greater than those of the other parts with a higher cooling rate. Thus, this effect decreased the difference between the properties at different positions within the wheel possessing different cooling rates.

However, the results showed that the mechanical properties became worse when the content of RE in the AlTiB$\mathrm{RE}$ grain refiner reached $0.16 \mathrm{wt} \%$. This trend was similar to the refining effects of $\mathrm{AlTiB}$ and $\mathrm{AlTiB}-\mathrm{RE}$ refiners in the A356 alloy wheel (Fig. 6).

\section{Discussion}

From the experimental and industrial results of the A356 alloy wheel, it can be noted that the AlTiB-RE refiner had better refinement effects than the RE and the conventional AlTiB refiners. The comprehensive properties of the alloy wheel refined by the AlTiB-RE refiner, especially in the spoke, which influenced the properties of the whole wheel to the greatest extent, were significantly improved. Also, the difference between the properties at different locations within the wheel with varying cooling rates decreased. This finding might be due to the lower cooling rate sensitivity of the AlTiB-RE grain refiner than that of the AlTiB refiner.

According to the phase diagram, the solid solubility of RE in $\alpha$-Al was very low, measuring approximately $0.05 \mathrm{wt} \%$ at the eutectic temperature [16]. During the nucleation and growth, RE easily gathered in the front of the solid-liquid interface because of the solute redistribution. According to the report of Wang et al. [10], the value of constitutional supercooling parameter of RE (Ce) was much higher than that of other elements such as $\mathrm{Ti}$ and Fe. Thus, a strong constitutional undercooling occurred, which decreased the growth rate of the growing interface and restricted the growth of nucleation of $\alpha$-Al. Next, the enriched RE adsorbed concentrated alloy elements, such as Ti, Fe and Si, resulting in the changing concentration gradient of the solidliquid interface. The undercooling changed with the concentration gradient. Tsai et al. [15] showed the thermal analysis curves of A356 alloy with the addition of La during solidification. The eutectic growth temperature of A356 alloy was $577^{\circ} \mathrm{C}$. Upon adding $1.0 \mathrm{wt} \% \mathrm{La}$ in the alloy, the eutectic growth temperature was lowered to $562{ }^{\circ} \mathrm{C}$. From the cooling curves and the undercooling could be calculated $[17,18]$. The results showed that the undercooling for $\alpha-\mathrm{Al}$ nucleation decreased due to RE addition. Therefore, the 
heterogeneous nucleation of $\alpha$-Al after adding AlTiB-RE refiner could occur at a lower degree of undercooling. The extent of undercooling was proportional to the efficiency of the grain refiner in providing potent nucleating sites [19, 20]. Thus, AlTiB-RE grain refiner showed lower cooling rate sensitivity than the AlTiB alone.

In addition, the AlSiTiRE intermetallic compounds in the microstructure (Fig. 7) exhibited a high melting point and could also act as heterogeneous nucleation sites for $\alpha-$ $\mathrm{Al}$ nucleation. It consequently suppressed the growth of $\alpha$ $\mathrm{Al}$, which was also confirmed by Zhao et al. [21]. Furthermore, the composition and size of $\beta-\left(\mathrm{Al}_{5} \mathrm{FeSi}\right)$ changed, which weakened the influence of $\beta-\left(\mathrm{Al}_{5} \mathrm{FeSi}\right)$, contributing to the property improvement.

However, if the RE content was too high, the volume fraction and the size of the RE-containing intermetallic compounds in the alloy exceeded a certain value, the microstructure and mechanical properties of the alloy were affected because the RE-containing compounds lost the heterogeneous nucleation effect. The similar phenomenon was also identified when Er was added in A356 alloy, as shown by Shi et al. [22]. Especially, in the case of using $\mathrm{Sr}$ as a modifier, the excess RE would react with Sr to form RE-Sr containing intermetallic phase with a size of approximately $50 \mu \mathrm{m}$, affecting the modification effect of eutectic $\mathrm{Si}$, as evidenced by Fig. 7. Therefore, the refining effects and the corresponding properties of the alloy with the addition of AlTiB-RE presented the tendency of increase and subsequent initial decrease with increasing RE content.

\section{Conclusions}

1. Among three different types of the grain refiners, AlTiB-RE refiner was less sensitive to the cooling rate than the AlTiB refiner and the RE refiner. AlTiB and RE exhibited synergetic refining effects than the individual refiners of AlTiB or RE.

2. With the cooling rate variation from the wheel hub to the inner rim sections, the variation extent of refinement effect with the addition of the AlTiB-RE refiner was only $43.2 \%-50.2 \%$ of the alloy with the addition of the conventional AlTiB refiner.

3. In comparison with the alloy wheel with an addition of the conventional AlTiB refiner, the comprehensive properties of the alloy wheel with the addition of the AlTiB-RE refiner were improved significantly. The improvement in the tensile strength, yield strength, and elongation in the spoke with a low cooling rate was of approximately $11.3,10.8$, and $44.1 \%$, respectively. This improvement was considerably greater than that in the other parts of wheel with a high cooling rate. The difference between the values of the tensile strength, yield strength, and elongation at different positions of the wheel decreased from $14.8 \%, 31.2 \%$, and $47.7 \%$ to $8.6 \%, 27.1 \%$, and $30.9 \%$, respectively.

Acknowledgment This work was financially supported by the National High Technology Research and Development Program (No. 2013AA031002).

\section{References}

[1] M. Zhu, Z.Y. Jian, G.C. Yang, Y.H. Zhou, Mater. Des. 36, 243 (2012)

[2] Q. Liu, H. Zhang, Y.X. Cui, Q.C. Li, Scr. Mater. 25, 371 (1991)

[3] H.R. Sergio, E.G. Rafael, K.D. Dheerendra, H.B. Víctor, F.Z. Horacio, J.P.L. María, Mater. Des. 32, 1865 (2011)

[4] C.W. Liao, J.C. Chen, Y. Li, R. Tu, C.X. Pan, J. Mater. Sci. Technol. 28, 524 (2012)

[5] Y.F. Han, K. Li, J. Wang, D. Shu, B.D. Sun, Mater. Sci. Eng. A 405, 306 (2005)

[6] M. Nowak, L. Bolzoni, B.N. Hari, Mater. Des. 66, 366 (2015)

[7] W. Schneider, M.A. Kearns, M.J. McGarry, A.J. Whitehead, in A Comparison of the Behaviour of AlTiB and AlTiC Grain Refiners, Light Metals, ed. by B.J. Welch (Warrendale, PA: TMS, 1998), pp. 953-961

[8] A.L. Greer, A.M. Bunn, A. Tronche, Acta Mater. 48, 2823 (2000)

[9] Q.Y. Xu, Y.J. Chen, T.Y. Huang, Chinese Patent ZL200610011786.2 May 2009

[10] K. Wang, C.X. Cui, Q. Wang, S.J. Liu, C.S. Gu, Mater. Lett. 85, 153 (2012)

[11] K. Wang, C.X. Cui, Q. Wang, L.C. Zhao, Y. Hu, J. Rare Earths 31, 313 (2013)

[12] O.E. Sebaie, A.M. Samuel, F.H. Samuel, H.W. Doty, Mater. Sci. Eng. A 480, 342 (2008)

[13] J.H. Li, X.D. Wang, T.H. Ludwig, Y. Tsunekawa, L. Arnberg, J.Z. Jiang, P. Schumacher, Acta Mater. 84, 153 (2015)

[14] W.M. Jiang, Z.T. Fan, Y.C. Dai, C. Li, Mater. Sci. Eng. A 597, 237 (2014)

[15] Y.C. Tsai, C.Y. Chou, S.L. Lee, C.K. Lin, J.C. Lin, S.W. Lim, J. Alloys Compd. 487, 157 (2009)

[16] V. Raghavan, J. Phase Equilibria Diffus. 28, 456 (2007)

[17] L.Y. Zhang, Y.H. Jiang, Z. Ma, S.F. Shan, Y.Z. Jia, C.Z. Fan, W.K. Wang, J. Mater. Process. Technol. 207, 107 (2008)

[18] A. Abedi, M. Shahmiri, B.A. Esgandari, B. Nami, J. Mater. Sci. Technol. 29, 971 (2013)

[19] B.S. Murty, S.A. Kori, M. Chakraborty, Int. Mater. Rev. 47, 3 (2002)

[20] C.L. Xu, Q.C. Jiang, Mater. Sci. Eng. A 437, 451 (2006)

[21] H.L. Zhao, Y. Song, M. Li, S.K. Guan, J. Alloys Compd. 508, 206 (2010)

[22] Z.M. Shi, Q. Wang, G. Zhao, R.Y. Zhang, Mater. Sci. Eng. A 626, 102 (2015) 